International Journal of

Environmental Research and

Public Health

ISSN 1660-4601

www.mdpi.com/journal/ijerph

Article

\title{
Locations that Support Social Activity Participation of the Aging Population
}

\author{
Pauline van den Berg *, Astrid Kemperman, Boy de Kleijn and Aloys Borgers \\ Eindhoven University of Technology, P.O. Box 513, 5600MB Eindhoven, The Netherlands; \\ E-Mails: a.d.a.m.kemperman@tue.nl (A.K.); boydekleijn@hotmail.com (B.K.); \\ a.w.j.borgers@tue.nl (A.B.) \\ * Author to whom correspondence should be addressed; E-Mail: p.e.w.v.d.berg@tue.nl; \\ Tel.: +31-40-247-5417; Fax: +31-40-243-8488.
}

Academic Editor: Paul B. Tchounwou

Received: 22 June 2015 / Accepted: 24 August 2015 / Published: 26 August 2015

\begin{abstract}
Social activities are an important aspect of health and quality of life of the aging population. They are key elements in the prevention of loneliness. In order to create living environments that stimulate older adults to engage in social activities, more insight is needed in the social activity patterns of the aging population. This study therefore analyzes the heterogeneity in older adults' preferences for different social activity location types and the relationship between these preferences and personal and mobility characteristics. This is done using a latent class multinomial logit model based on two-day diary data collected in 2014 in Noord-Limburg in the Netherlands among 213 respondents aged 65 or over. The results show that three latent classes can be identified among the respondents who recorded social activities in the diary: a group that mainly socializes at home, a group that mainly socializes at a community center and a group that is more likely to socialize at public 'third' places. The respondents who did not record any interactions during the two days, are considered as a separate segment. Relationships between segment membership and personal and mobility characteristics were tested using cross-tabulations with chi-square tests and analyses of variance. The results suggest that both personal and mobility characteristics play an important role in social activity patterns of older adults.
\end{abstract}

Keywords: social contact; interaction; elderly; living environment; amenities; latent class 


\section{Introduction}

The ageing of the population poses challenges for urban and transport planners to create living environments that support older adults' health and quality of life. This implies that opportunities for social contacts should be created that are accessible for older adults. Compared to their younger counterparts, older people are in general less mobile, spend more time at home, and participate in fewer social settings (e.g., work, school or sports clubs), which probably makes them more reliant on their neighborhood for social contacts. Neighborhood services and facilities such as shops, sports facilities, cafés and restaurants, community centers, and recreational areas can provide opportunities for social contacts among residents. However, the number of local facilities is decreasing due to increasing mobility, regionalization, Internet-use, and demographic decline in certain areas (e.g., Oldenburg, 1989 [1]; Hickman, 2013 [2]; CBS, 2015 [3]). This may have negative outcomes for the social participation of older adults and consequently their quality of life. A lack of social participation may result in social isolation and loneliness, which may cause a reduction in physically activity, and both mental and physical health (British Columbia, 2014 [4]). In order to promote healthy aging it is crucial to stimulate social contacts among older adults. Creating environments that support social participation of the ageing population is therefore an important challenge for urban and transport planners.

For successful urban and transport planning for the aging population, more insight is needed in seniors' choices for social activity locations and the extent to which social contacts take place at different (local) facilities. The aim of this study therefore is to analyze the diversity of older adults' preferences for different social activity location types and the relationship between these preferences and personal and mobility characteristics. This is done by estimating a latent class multinomial logit model of individuals' social interaction location choices based on data collected among 213 respondents aged 65 or over collected in 2014 in several towns in Noord-Limburg in the southeast of the Netherlands.

This article first describes the existing literature on social activity patterns of older adults. Next, the data collection and analysis methods are described, followed by the description of the results. The article finishes with a discussion of the findings and the implications for urban and transport policy.

\section{Literature}

Many countries all over the world are experiencing a sharp rise in the ageing population. Ageing is in general associated with decreased health, mobility and social participation, and changes in the size and composition of one's social network (e.g., through retirement or loss of a partner), which impacts activities such as traveling and socializing, and consequently, quality of life. Several studies in transportation research have focused on travel behavior of older adults (e.g., Tacken, 1998 [5]; Alsnih and Hensher, 2003 [6]; Silvis and Niemeier, 2009 [7]; Mercado and Páez, 2009 [8]; Mohammadian et al., 2013 [9]; Horner et al., 2015 [10]). The literature shows that the elderly have become more mobile compared to earlier generations in terms of travel frequency, distance (e.g., Rosenbloom, 2001 [11]; Collia et al., 2003 [12]; Páez et al., 2006 [13]) and car ownership (Schmöcker et al., 2005 [14]; Bannister and Bowling, 2004 [15]; Newbold et al., 2005 [16]). Among the elderly, the car is the preferred mode (Kim and Ulfarsson, 2004 [17]; Collia et al., 2003 [12]; Kemperman and Timmermans, 2009 [18]), followed by walking. In the Netherlands, a relatively large 
share of elderly trips is made by bicycle (Tacken, 1998 [5]; Kemperman and Timmermans, 2009 [18]; Van den Berg et al., 2011 [19]). However, the travel frequency and distance of older people are still significantly lower compared to those of younger people. This holds especially for the oldest group of elderly, for women and elderly with walking disabilities (e.g., Collia et al., 2003 [12]).

Older people also perform fewer social activities (Aoki et al., 1996 [20]; Páez et al., 2006 [13]; Kemperman et al., 2006 [21]; Carrasco and Miller, 2006 [22]; Farber and Paéz, 2009 [23]) and have a smaller social network than their younger counterparts (e.g., Van den Berg et al., 2009 [24]). As a result, seniors have a heightened risk of social isolation and loneliness (e.g., Hawkley et al., 2008 [25]; Scharf and De Jong Gierveld, 2008 [26]; De Jong Gierveld and Van Tilburg, 2010 [27]; Pino et al., 2014 [28]; Weijs-Perrée et al., 2015 [29]; Van den Berg et al., in press [30]), which in turn carries the risk of being less physically active, and having reduced mental and physical health (British Columbia, 2014 [4]). In order to reduce these risks it is crucial to stimulate older adults' social participation.

Social networks can provide people with access to instrumental resources and emotional support. Social network ties can be developed and maintained through face-to-face social interaction or communication through different ICTs. Studies investigating the relationship between face-to-face and ICT-mediated social interactions have shown that ICT-mediated contacts complement face-to-face contacts (e.g., Mokhtarian et al., 2006 [31]; Frei and Axhausen, 2008 [32]; van den Berg et al., 2012 [33]; Carrasco, 2011 [34]). However, the elderly still lag behind in the use of communication technology. Moreover, according to the study by Cummings et al. (2002) [35] face-to-face social interactions are more useful than digital interactions for developing and sustaining social relationships. This study therefore focuses on face-to-face social contacts.

Older adults particularly rely on their neighbourhood for social contacts because they spend more time at home, are less mobile and participate in fewer other settings such as work, school or sports clubs (e.g., Völker and Flap, 2007 [36]; van den Berg et al., forthcoming [37]). Policymakers are currently stimulating ageing in place, which is defined as "the ability to live in one's own home and community safely, independently, and comfortably, regardless of age, income, or ability level." (Centers for Disease Control and Prevention, 2014 [38]). For ageing in place to be successful, neighborhoods should meet the needs of older adults and provide access to face-to-face social activities.

The aging of the population poses challenges for urban and transport planners to provide sufficient levels of accessibility for older adults. The concept of accessibility deals with the activity locations in a given area and the effectiveness with which people can reach these, given the available transportation system (Horner et al., 2015 [10]). Accessible local facilities may provide opportunities for social interaction and expansion and maintenance of local social networks (e.g., Talen, 1999 [39]; Oldenburg, 1989 [1]; Dempsey et al., 2012 [40]; Francis et al., 2012 [41]; Hickman, 2013 [2]). Horner et al. (2015) [10] studied the differences in accessibility to activities and facilities among different age groups. Their findings indicate that the youngest age group (18-49) has the highest level of accessibility. Older adults have lower accessibility, with the lowest level for the middle age group (50-64). The finding that the oldest age group does not have the lowest access to facilities is probably related to the fact that retirement homes tend to cluster around (health care) facilities.

In a previous study we found accessibility, mobility and satisfaction with the facilities in the neighborhood can decrease feelings of loneliness (van den Berg et al., 2015 [30]). However, the number and quality of local services and facilities such as shops, schools, sports facilities, cafés, 
community centers, libraries and recreational areas has decreased over the last decades (e.g., Oldenburg, 1989 [1]; Hickman, 2013 [2]; CBS, 2015 [3]). For instance, in the Netherlands the number of facilities per 1000 inhabitants has decreased with $8 \%$ between 2001 and 2005. The number of food shops per 1000 inhabitants even decreased with $18 \%$ and the number of banking offices decreased with 38\% (CBS, 2015 [3]). There are a number of reasons for this trend. Increasing mobility and increasing use of the Internet (e-commerce) have lowered the demand for local facilities. In addition, economic recession seems to aggravate this trend (Hickman, 2013 [2]). This trend may hamper older adults' social participation, as local public facilities have been found to be important for social interaction.

Hickman (2013) [2] studied the role of public facilities for social interaction in deprived neighborhoods in Great Britain based on 180 in-depth interviews. He found that residents particularly value shops for social interaction. Parks and community centers were also valued, especially by people who spent more time at home, such as the elderly. Francis et al. (2012) [41] studied the role of public facilities for creating sense of community in Perth, Australia. Analyzing survey data from 911 respondents they found that shops and public open space contribute to sense of community. They found community centers and schools to be less relevant. Whalen et al. (2012) [42] also found that shops and services in the neighborhood are important for creating a sense of community. Based on social interaction diary data collected from 747 respondents in the Eindhoven area, Van den Berg et al. (2014) [43] estimated a latent class model on social interaction location choice. Their results indicated that a relatively large segment mainly performed social activities at home. A second segment preferred social interactions at work. A third segment was more likely to have social contacts at public space outdoors and school or childcare facilities, while the fourth segment preferred cafés, restaurants, and sports facilities. Segment membership was explained by personal and household characteristics such as gender, age, household type, number of face-to-face social interactions, and frequency of contact with neighbors, as well as characteristics of the residential environment such as urban density, distance to several facilities (supermarket, family doctor and community center) and satisfaction with local facilities.

Although the discussed studies acknowledged the importance of public facilities for social interaction, they did not focus specifically on the importance of these facilities for the elderly. For successful urban design and planning for the growing aging population, more knowledge is needed on their spatial choices for social activities. When studying senior citizens and their social activity patterns, their heterogeneity should be incorporated. Their difference in social activity patterns may be reflected by differences in personal and household characteristics, characteristics of the residential location and the use of different transport modes. Therefore, this article presents the results of a latent class multinomial logit model of older adults' social interaction location choices, followed by the results of bivariate analyses used to analyze the links between latent class membership and several personal, residential and mobility attributes.

\section{Methods}

\subsection{Data Collection}

The data for this study were collected using a two-day social interaction diary and a questionnaire. In the diary respondents were asked for a number of different types of locations, whether they had visited that type of location, and whether they had had contact with other persons at that location. For each 
contact they were asked to indicate start and end time, whether the interaction was preplanned, routine or spontaneous, with whom they interacted, the purpose of the interaction, and how important the interaction was for them. The questionnaire was used to collect data on personal and mobility characteristics.

The data were collected in several towns in Noord-Limburg, which is located in the southeast of the Netherlands. Noord-Limburg, the northern part of the province Limburg, consists of the municipalities Beesel, Bergen, Gennep, Horst aan de Maas, Mook en Middelaar, Peel en Maas, Venlo and Venray (see Figure 1). The area inhabits 280,600 people, out of whom $18 \%$ is 65 or over. The area is expecting a demographic decline and increased ageing, which is expected to result in $3 \%$ less inhabitants in 2030, out of whom $28 \%$ will be 65 and over. This percentage is higher than the expected percentage of older adults in the Dutch population (24\%) in 2030. This makes Noord-Limburg an interesting study area for this research.

In order to have variation with respect to the living environment, data were collected in areas that differed with respect to urban density. The degree of urbanization was measured based on the "surrounding address density", which is the average number of addresses per 500 meter square within a kilometer radius from the address. This indicator has been widely used in the Netherlands and consists of five categories: very strongly urbanized (surrounding address density of 2500 and over per $\mathrm{km}^{2}$ ), strongly urbanized (surrounding address density between 1500 and 2500 per $\mathrm{km}^{2}$ ), moderately urbanized (surrounding address density between 1000 and 1500 per $\mathrm{km}^{2}$ ), little urbanized (surrounding address density between 500 and 1000 per $\mathrm{km}^{2}$ ), and not urbanized (surrounding address density below 500 per $\mathrm{km}^{2}$ ). In Noord-Limburg, only $2 \%$ of the inhabitants live in a very high urban density area, namely in the center of Venlo. This highest density class is therefore merged with the second class. Equal numbers of diaries were distributed in each of the four density classes.

The data were collected between January and March 2014 using a deliver and pick up procedure, which resulted in a good response. Eighty-eight percent of the accepted diaries were returned and useful for the analyses. A total of 213 social interaction diaries were collected among respondents 65 or over. 

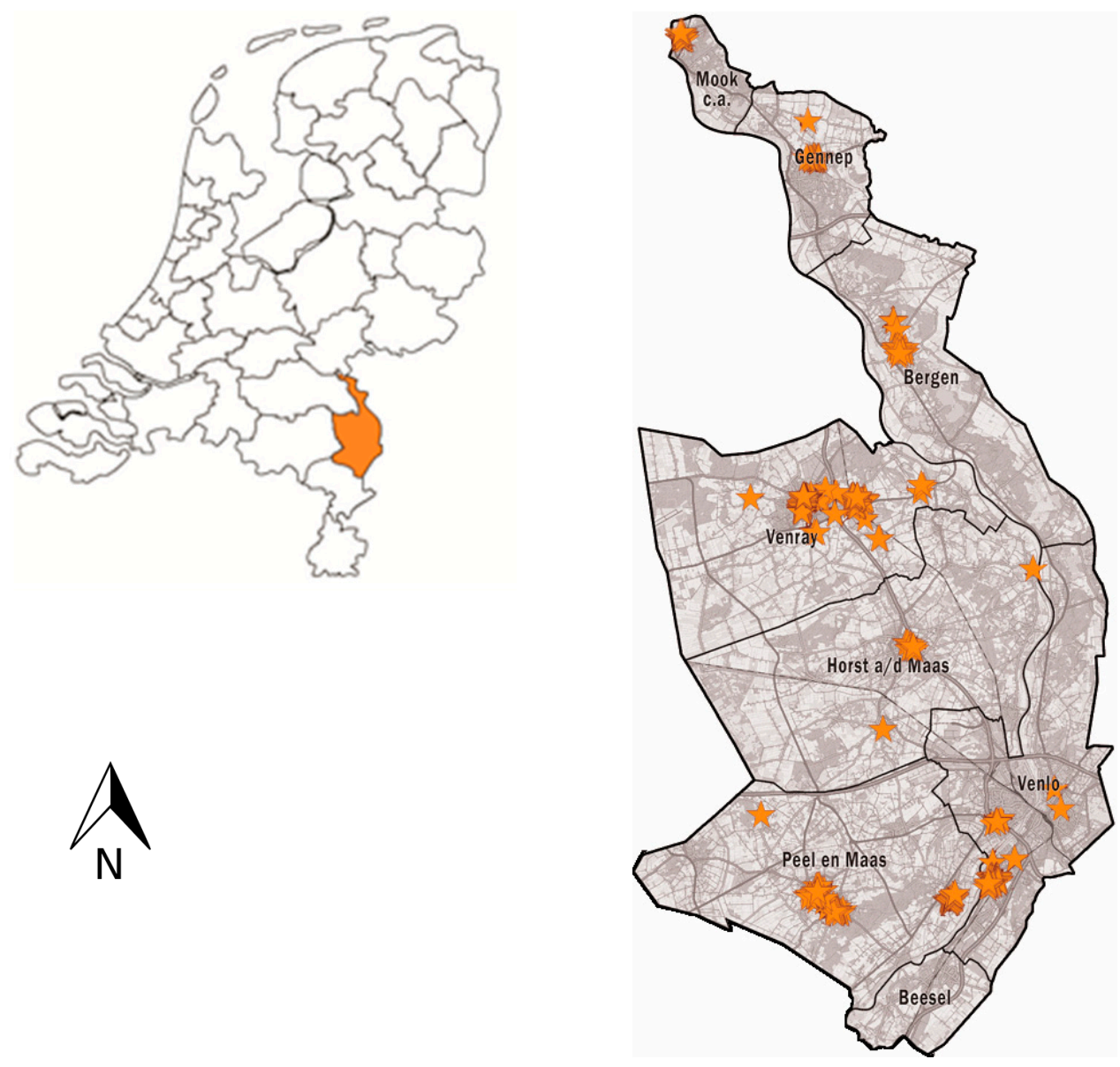

Figure 1. Map of Noord-Limburg and sampling locations.

\subsection{Latent Class Multinomial Logit Model}

To analyze the heterogeneity in social interaction location choices among older adults a latent class multinomial logit model is used (Greene 2002) [44]. This model groups the respondents into segments (latent classes). For each segment separate parameters are estimated showing their preferences for social interaction locations. The respondents who did not record any interactions are not included in the model. They are considered as a separate segment. The model accounts for the hierarchical structure of the data in which the number of social activities may very across respondents.

A fixed number of S segments is assumed to exist in the population. Given that an individual belongs to latent class $s(s=1, \ldots, S)$, the utility function for individual $i$ for social interaction location $j$ on choice occasion $\mathrm{t}$ can be expressed as follows,

$$
U_{i j t}^{S}=\beta_{s}^{\prime} X_{i j t}+\varepsilon_{i j t}
$$

where Xijt expresses all social interaction location type alternatives and $\beta \_s^{\wedge \prime}$ is a parameter vector for each latent class s. eijt is an error term representing unobserved heterogeneity for individual $i$ and location type $\mathrm{j}(\mathrm{j}=1, \ldots, \mathrm{J})$ at occasion $\mathrm{t}$. For each segment or latent class the choice probabilities are generated, resulting in the latent class multinomial model: 


$$
P(j \mid \text { segment }=s)=\frac{\exp \left(\beta_{s}^{\prime} X_{i j t}\right)}{\sum_{j \prime=1} \exp \left(\beta_{s}^{\prime} X_{i j / t}\right)}
$$

The latent class specific probabilities are a set of fixed constants that sum to one. The multinomial logit (MNL) model estimates the probability of individual i belonging to latent class s:

$$
P\left(y_{i j}=j\right)=\sum_{s=1}^{S} P(\text { segment }=s)\left[\frac{\exp \left(\beta_{s}^{\prime} X_{i j t}\right)}{\sum_{j^{\prime}=1} \exp \left(\beta_{s}^{\prime} X_{i j \prime}\right)}\right]
$$

Each individual is then assigned to the latent class with the highest probability. The latent class parameters can be estimated using maximum likelihood estimation. The goodness of fit of the model is indicated by McFadden's rho square $(\rho 2=1-L L(\beta) / L L(0))$. The likelihood ratio test is used to check whether the estimated model performs better than the base model. This is the case if the $X^{2}$ value is higher than the critical $X^{2}$ value.

The relationship between latent class membership of the respondents and their personal and household characteristics, and mobility characteristics is tested using cross-tabulations (with Chi-square tests) and analysis of variance (with $\mathrm{F}$ ratio tests).

\section{Results}

\subsection{Sample Characteristics}

The sample consists of 213 respondents aged 65 or over. The characteristics of the sample are summarized in Table 1. As can be seen, the sample contains more women than men. One third of the sample is between 65 and 69 and a quarter of the respondents are 80 or over. Regarding household composition, the results show that more than one third of the respondents are single and the other two thirds live with a partner. Almost half of the respondents are lower educated. Ten percent of the respondents is severely physically challenged, and another $21 \%$ is somewhat physically challenged. As can be seen, the sample is roughly evenly distributed over the four classes of urban density.

\subsection{Social Activity Characteristics}

Out of the 213 respondents, $22(10 \%)$ did not record any face-to-face social interactions in two days. The other 191 recorded a total of 1029 social interactions. The maximum number of interactions recorded in two days was 15 . Overall, the average number of interactions in two days is 4.83 , with a standard deviation of 3.28. The distribution of number of interactions can be seen in Figure 1 . 
Table 1. Sample characteristics $(\mathrm{N}=213)$.

\begin{tabular}{lccc}
\hline Variable & Levels & $\mathbf{N}$ & $\mathbf{\%}$ \\
\hline Gender & Male & 91 & 43 \\
\hline Age & Female & 120 & 57 \\
\hline & $65-69$ & 74 & 35 \\
\hline & $70-74$ & 44 & 21 \\
\hline Household composition & $75-79$ & 43 & 20 \\
\hline Education & $80+$ & 52 & 24 \\
\hline & Single & 79 & 37 \\
\hline Couple & 134 & 63 \\
\hline Gross yearly household income & Primary & 95 & 45 \\
\hline & Medium & 51 & 24 \\
\hline High $($ BSc or higher $)$ & 59 & 28 \\
\hline$<€ 21,000$ & 34 & 16 \\
\hline Physically challenged & $€ 21,000-€ 34,000$ & 71 & 33 \\
\hline & $€ 34,000-€ 43,000$ & 51 & 24 \\
\hline Urban density & $>€ 43,000$ & 34 & 16 \\
\hline & Yes, severely & 21 & 10 \\
\hline & Yes, somewhat & 44 & 21 \\
\hline No & 143 & 67 \\
\hline & High $\left(>1500\right.$ addresses $\left./ \mathrm{km}^{2}\right)$ & 62 & 29 \\
\hline & Low $\left(500-1000\right.$ addresses $\left./ \mathrm{km}^{2}\right)$ & 45 & 31 \\
\hline & & 40 & 21 \\
\hline & Very $\left(<500\right.$ addresses $\left./ \mathrm{km}^{2}\right)$ & 19 \\
\hline
\end{tabular}

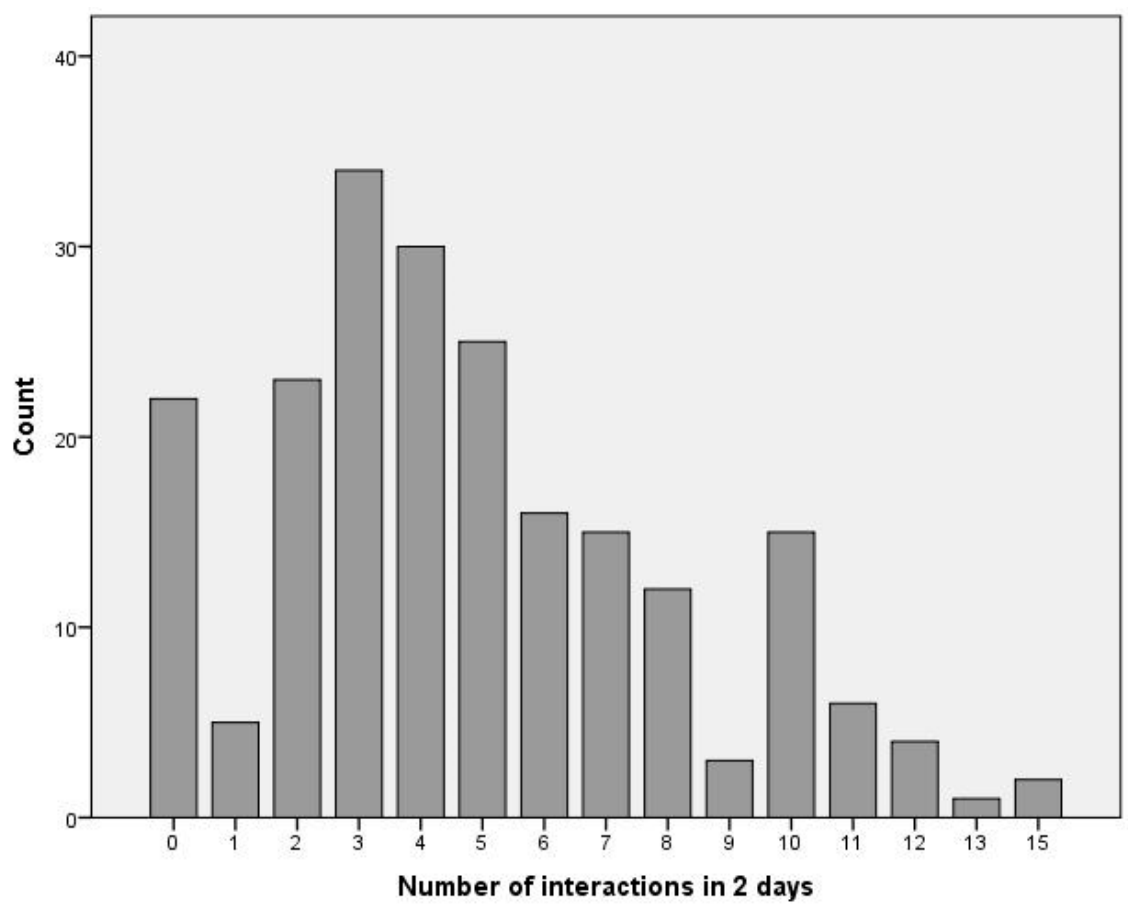

Figure 2. Number of recorded interactions in two days $(\mathrm{N}=213)$. 
Table 2 shows the distribution of the 1029 social interactions across types of location. On the left it shows the 19 different location types as recorded in the diary. For the analyses the location types were recorded into seven categories, which are shown on the right. As can be seen, home is the most common location for social interaction, followed by home of another person. In total, over one third of social interactions took place at a home location. Almost $15 \%$ of the interactions took place in public space outdoors, including parks and play facilities. The categories community center and church were merged. Together they account for $11 \%$ of the social interactions. This percentage is high compared to Van den Berg et al. (2014) [43], indicating that community centers are specifically important for older adults in less urbanized areas. Different types of shopping facilities were merged with health facilities. The category shop/services contains $18 \%$ of the social interactions. Five percent of the interactions took place at a bar or restaurant and 6\% took place at a sports facility. As older adults typically do not work or study anymore, social interactions at work or school make up only a small part of social interactions. For this reason, these locations were merged with the category "other".

The respondents were asked for each social interaction to indicate on a five point scale how important the interaction was to them. Table 3 shows the mean scores of importance of interactions for each type of location. As shown, social interactions at a bar or restaurant have the highest score on importance, followed by interactions at home. Social interactions at a community center or church have the lowest importance.

Table 2. Distribution of social interactions across types of location.

\begin{tabular}{|c|c|c|c|c|c|}
\hline $\begin{array}{l}\text { Recorded in Diary } \\
\text { Type of Location }\end{array}$ & $\mathbf{N}$ & $\%$ & $\begin{array}{l}\text { Used in LCModel } \\
\text { Type of Location }\end{array}$ & $\mathbf{N}$ & $\%$ \\
\hline Home & 194 & 18.9 & \multirow{2}{*}{ Home location } & \multirow{2}{*}{367} & \multirow{2}{*}{35.7} \\
\hline Home other person & 173 & 16.8 & & & \\
\hline On the road & 25 & 2.4 & \multirow{4}{*}{ Public space/park } & \multirow{4}{*}{153} & \multirow{4}{*}{14.9} \\
\hline Public space outdoors & 84 & 8.2 & & & \\
\hline Park & 23 & 2.2 & & & \\
\hline Play facility & 21 & 2.0 & & & \\
\hline Community center & 94 & 9.1 & \multirow{2}{*}{ Community center/church } & \multirow{2}{*}{117} & \multirow{2}{*}{11.4} \\
\hline Church & 23 & 2.2 & & & \\
\hline Supermarket & 84 & 8.2 & \multirow{4}{*}{ Shop/services } & \multirow{4}{*}{186} & \multirow{4}{*}{18.1} \\
\hline Local shop & 21 & 2.0 & & & \\
\hline Shopping center & 44 & 4.3 & & & \\
\hline Health facility & 37 & 3.6 & & & \\
\hline Bar & 17 & 1.7 & \multirow{2}{*}{ Bar/restaurant } & \multirow{2}{*}{46} & \multirow{2}{*}{4.5} \\
\hline Restaurant & 29 & 2.8 & & & \\
\hline Sports facility & 62 & 6.0 & Sports facility & 62 & 6.0 \\
\hline Library & 2 & 0.2 & \multirow{4}{*}{ Other } & \multirow{4}{*}{98} & \multirow{4}{*}{9.5} \\
\hline Work & 11 & 1.1 & & & \\
\hline School & 22 & 2.2 & & & \\
\hline Other & 63 & 6.1 & & & \\
\hline Total & 1029 & 100 & Total & 1029 & 100 \\
\hline
\end{tabular}


Table 3. Mean importance of interactions per location type.

\begin{tabular}{lc}
\hline Type of Location & Importance (1-5) \\
\hline Home location & 4.01 \\
\hline public space /park & 3.85 \\
\hline Community center/church & 3.47 \\
\hline Shop/services & 3.88 \\
\hline Bar/restaurant & 4.38 \\
\hline Sports facility & 3.72 \\
\hline Other & 3.73 \\
\hline Total & 3.82 \\
\hline \multicolumn{2}{c}{$\mathrm{F}=14.532, p<0.000}$. \\
\end{tabular}

\subsection{Latent Class Multinomial Logit Model}

To analyze how the use of social interaction locations differs between respondents we use a latent class multinomial logit (MNL) model. Table 4 shows the estimation results of the latent class model as well as the conventional MNL model. The likelihood ratio test shows that the $\mathrm{X}^{2}$ value exceeds the critical $\mathrm{X}^{2}$ value which indicates that the estimated model performs better than the base model. Parameters are estimated for the categories: public space/park, shop/services, community center/church, bar/restaurant, sports facility and other type of location. The category "home location" serves as the reference category, which means that the estimated parameters should be interpreted relative this location type. The parameters for the conventional MNL model show the average likelihood for each location and are included for reasons of comparison. The parameters for the latent class MNL model indicate whether a specific segment is more or less likely than average to socialize at a certain type of location.

Three segments were identified, showing different parameters for social interaction locations. The first segment can be labeled as home socializers. This segment mainly has social contacts at a home location, which can be their own, or another person's home. This segment contains $139(65 \%)$ respondents. The second segment is described as third place socializers and contains $18(9 \%)$ respondents. This segment is less likely to socialize at home and more likely than average to socialize at all other six types of locations. Shops and services have the highest parameter, followed by public space or park. The third segment, consisting of $34(16 \%)$ respondents, can be labeled community center socializers, as they are more likely than average to socialize at a community center or church. The remaining $22(10 \%)$ respondents who did not record any interactions make up a fourth segment which is labeled non-socializers. This segment is not included in Table 4. It will however be included in the next analyses. 
Table 4. Modeling results.

\begin{tabular}{|c|c|c|c|c|c|c|c|c|}
\hline \multirow{3}{*}{ Variable } & \multirow{2}{*}{\multicolumn{2}{|c|}{$\begin{array}{l}\text { Conventional } \\
\text { MNL Model }\end{array}$}} & \multicolumn{6}{|c|}{ Latent Class Model } \\
\hline & & & \multicolumn{2}{|c|}{$\begin{array}{c}\text { Home } \\
\text { Socializers }\end{array}$} & \multicolumn{2}{|c|}{$\begin{array}{l}\text { Third Place } \\
\text { Socializers }\end{array}$} & \multicolumn{2}{|c|}{$\begin{array}{l}\text { Community } \\
\text { Center } \\
\text { Socializers }\end{array}$} \\
\hline & $\mathrm{B}$ & Sig. & $\mathrm{B}$ & Sig. & $\mathrm{B}$ & Sig. & $\mathrm{B}$ & Sig. \\
\hline Public space/park & -0.875 & 0.000 & -1.055 & 0.000 & 1.785 & 0.000 & -1.102 & 0.000 \\
\hline Shop/service & -0.680 & 0.000 & -1.068 & 0.000 & 2.494 & 0.000 & -0.674 & 0.004 \\
\hline Community center & -1.143 & 0.000 & -2.244 & 0.000 & -0.638 & 0.364 & 0.825 & 0.000 \\
\hline Bar/restaurant & -2.077 & 0.000 & -2.768 & 0.000 & 0.774 & 0.136 & -0.815 & 0.001 \\
\hline Sports facility & -1.778 & 0.000 & -1.885 & 0.000 & 0.889 & 0.068 & -3.434 & 0.000 \\
\hline Other & -1.320 & 0.000 & -1.256 & 0.000 & -0.604 & 0.345 & -2.734 & 0.000 \\
\hline Segment probability & & & 0.73 & & 0.09 & & 0.18 & \\
\hline $\begin{array}{l}\text { Log likelihood } \\
\text { function } L L(\beta)\end{array}$ & \multicolumn{2}{|c|}{-1790.082} & \multicolumn{2}{|c|}{-1714.367} & & & & \\
\hline $\begin{array}{l}\text { Restricted log } \\
\text { likelihood } L L(0)\end{array}$ & \multicolumn{2}{|c|}{-2002.342} & \multicolumn{2}{|c|}{-2002.342} & & & & \\
\hline Likelihood ratio test & \multicolumn{2}{|c|}{$X^{2}=151.43$} & \multicolumn{2}{|c|}{$\mathrm{Df}=12$} & \multicolumn{4}{|c|}{ Critical $X^{2}(p=0.05)=21.03$} \\
\hline McFadden $\mathrm{R}^{2}$ & \multicolumn{2}{|c|}{0.106} & \multicolumn{2}{|c|}{0.144} & & & & \\
\hline
\end{tabular}

\subsection{Effect of Personal, Household and Mobility Characteristics}

Relationships between segment membership and personal and mobility characteristics were tested using cross-tabulations with chi-square tests and analyses of variance. The results are shown in Table 5. The results show no significant differences between segments with respect to gender. Regarding age we do find a significant difference between segments. The non-socializers are the oldest group, with an average age of almost 78 , followed by the community center socializers with an average age of 76.5. The third place socializers are the youngest group with an average age of almost 70 .

Regarding income and education level, significant differences between the segments are found as well. The third place socializers are more likely to have a higher income and a higher education. The community center socializers have the lowest income and $63 \%$ only has primary education. The non-socializers have the highest share $(77 \%)$ of low educated respondents. This is also related to the fact that this segment has the highest average age. The segments are also found to significantly differ with respect to household composition. The third place socializers are most likely to live with a partner, whereas the non-socializers are most likely single.

Urban density was also found to have a significant relationship with latent class membership. The results show that the highest share of non-socializers live in high urban density areas. The community center socializers are most likely to live in moderate density areas and the third place socializers are most likely to live in low urban density areas. These findings are in line with the idea that people living in more dense areas are less social in the sense that they have a smaller or less strong social network and fewer social interactions (e.g., Aoki et al., 1996 [20]; Van den Berg et al., 2009 [24]). These findings may also be related to the fact that the oldest and least mobile group of elderly tend to live in old age homes which are located in higher density areas in town centers. This corresponds with 
the findings of Horner et al. (2015) [10] indicating that the oldest age group has higher access to facilities as retirement homes tend to cluster around health care facilities. While more facilities are present in higher density areas, the frequency of use is lower. Thus, the presence of facilities alone does not guarantee its use by the elderly.

The results show that the home socializers are most likely to volunteer. The non-socializers are least likely to volunteer, followed by the third place socializers. As expected, the average number of social interactions recorded in the two-day diary, differs significantly between the segments. The non-socializers did not record any social interactions. The third place socializers recorded the highest number of social interactions, with an average of six interactions in two days. In line with these results, the average score for loneliness is highest for the non-socializers and lowest for the third place socializers. The same pattern is found with respect to perceived health. The non-socializers have the lowest score on perceived health and are more likely to be physically challenged, whereas the third place socializers score highest on self-rated health and are less likely to be physically challenged.

With respect to mobility, respondents were asked which transport modes they use. The results again show significant differences between the segments. The non-socializers are less likely than average to walk, cycle, drive a car and use public transport. The third place socializers have the highest shares of users for all four transport modes. This indicates that mobility plays an important role in older adults' social activity patterns.

Note that several variables in Table 5 are interrelated. For instance, higher age is associated with lower perceived health $(\mathrm{r}=-0.168 ; p<0.05)$ and fewer social interactions $(\mathrm{r}=-0.354 ; p<0.01)$. Self-perceived health is negatively correlated with feelings of loneliness $(\mathrm{r}=-0.267 ; p<0.01)$, indicating that poor health increases the likelihood of feeling lonely. Health is also related to mobility. Perceived health is higher for people who walk, cycle, use a car and use public transport. The difference in health rating is largest for car use.

Table 5. Relationships between segments and personal, household and mobility characteristics.

\begin{tabular}{|c|c|c|c|c|c|c|}
\hline & 1 & 2 & 3 & 4 & Total & \\
\hline Variable & $\begin{array}{c}\text { Home } \\
\text { Socializers } \\
(\mathrm{N}=139)\end{array}$ & $\begin{array}{c}\text { Third Place } \\
\text { Socializers } \\
(\mathbf{N}=\mathbf{1 8})\end{array}$ & $\begin{array}{l}\text { Community Center } \\
\text { Socializers }(\mathbf{N}=\mathbf{3 4})\end{array}$ & $\begin{array}{c}\text { Non- } \\
\text { Socializers } \\
(\mathbf{N}=\mathbf{2 2})\end{array}$ & $(\mathrm{N}=\mathbf{2 1 3})$ & $\begin{array}{c}X^{2} \text { or } F \\
\text { (sig.) }\end{array}$ \\
\hline \multicolumn{7}{|l|}{ Gender } \\
\hline Male (\%) & 43 & 33 & 53 & 36 & 43 & $\begin{array}{r}2.450 \\
(0.484)\end{array}$ \\
\hline Female (\%) & 57 & 67 & 47 & 64 & 57 & \\
\hline \multicolumn{7}{|l|}{ Age } \\
\hline Years mean & 73.47 & 69.94 & 76.50 & 77.77 & 74.10 & $\begin{array}{r}6.815 \\
(0.000)\end{array}$ \\
\hline \multicolumn{7}{|c|}{$\begin{array}{l}\text { Gross yearly household } \\
\text { income }\end{array}$} \\
\hline $\begin{array}{l}<€ 21,000 \\
(\%)\end{array}$ & 13 & 0 & 46 & 25 & 18 & $\begin{array}{l}25.159 \\
(0.000)\end{array}$ \\
\hline
\end{tabular}


Table 5. Cont.

\begin{tabular}{|c|c|c|c|c|c|c|}
\hline & 1 & 2 & 3 & 4 & Total & \\
\hline Variable & $\begin{array}{c}\text { Home } \\
\text { Socializers } \\
(\mathbf{N}=139) \\
\end{array}$ & $\begin{array}{c}\text { Third Place } \\
\text { Socializers } \\
(\mathbf{N}=18) \\
\end{array}$ & $\begin{array}{l}\text { Community Center } \\
\text { Socializers }(\mathbf{N}=\mathbf{3 4})\end{array}$ & $\begin{array}{c}\text { Non- } \\
\text { Socializers } \\
(\mathbf{N}=\mathbf{2 2}) \\
\end{array}$ & $\begin{array}{l}(N= \\
213)\end{array}$ & $\begin{array}{c}X^{2} \text { or } F \\
\text { (sig.) }\end{array}$ \\
\hline $\begin{array}{l}€ 21,000-€ 34,000 \\
(\%)\end{array}$ & 42 & 28 & 25 & 31 & 37 & \\
\hline$>€ 34,000(\%)$ & 45 & 72 & 29 & 44 & 45 & \\
\hline \multicolumn{7}{|l|}{ Education } \\
\hline Low (\%) & 42 & 11 & 63 & 77 & 46 & $\begin{array}{l}26.311 \\
(0.000)\end{array}$ \\
\hline Medium (\%) & 24 & 33 & 27 & 18 & 25 & \\
\hline High (\%) & 33 & 56 & 10 & 5 & 29 & \\
\hline \multicolumn{7}{|c|}{ Household composition } \\
\hline Single (\%) & 32 & 6 & 50 & 55 & 37 & $\begin{array}{l}14.595 \\
(0.002) \\
\end{array}$ \\
\hline Couple (\%) & 68 & 94 & 50 & 46 & 63 & \\
\hline \multicolumn{7}{|l|}{ Tenure } \\
\hline $\begin{array}{l}\text { Owner occupied } \\
(\%)\end{array}$ & 65 & 89 & 59 & 62 & 65 & $\begin{array}{c}5.202 \\
(0.158) \\
\end{array}$ \\
\hline Rented (\%) & 36 & 11 & 41 & 38 & 35 & \\
\hline \multicolumn{7}{|l|}{ Urban density } \\
\hline High (\%) & 31 & 28 & 12 & 46 & 29 & $\begin{array}{l}21.382 \\
(0.011) \\
\end{array}$ \\
\hline Moderate (\%) & 29 & 28 & 50 & 18 & 31 & \\
\hline Low $(\%)$ & 17 & 39 & 21 & 32 & 21 & \\
\hline Very low (\%) & 23 & 6 & 18 & 5 & 19 & \\
\hline \multicolumn{7}{|l|}{ Volunteers } \\
\hline Yes (\%) & 69 & 28 & 58 & 18 & 58 & $\begin{array}{l}27.775 \\
(0.000) \\
\end{array}$ \\
\hline No (\%) & 31 & 72 & 43 & 82 & 42 & \\
\hline \multicolumn{7}{|c|}{ Active club member } \\
\hline Yes (\%) & 81 & 94 & 97 & 82 & 85 & $\begin{array}{c}6.799 \\
(0.079) \\
\end{array}$ \\
\hline No (\%) & 19 & 6 & 3 & 18 & 15 & \\
\hline \multicolumn{7}{|c|}{ Face-to-face contact frequency } \\
\hline $\begin{array}{l}\text { Number in } 2 \\
\text { days }\end{array}$ & 5.51 & 6.00 & 4.56 & 0.00 & 4.83 & $\begin{array}{l}25.153 \\
(0.000) \\
\end{array}$ \\
\hline \multicolumn{7}{|l|}{$\begin{array}{l}\text { Perceived } \\
\text { loneliness }\end{array}$} \\
\hline $1-5$ & 1.86 & 1.61 & 1.93 & 3.19 & 1.95 & $\begin{array}{l}11.319 \\
(0.000) \\
\end{array}$ \\
\hline \multicolumn{7}{|l|}{ Perceived health } \\
\hline $1-5$ & 3.50 & 3.94 & 3.85 & 3.19 & 3.57 & $\begin{array}{r}3.514 \\
(0.016) \\
\end{array}$ \\
\hline
\end{tabular}


Table 5. Cont.

\begin{tabular}{|c|c|c|c|c|c|c|}
\hline & 1 & 2 & 3 & 4 & Total & \\
\hline Variable & $\begin{array}{c}\text { Home } \\
\text { Socializers } \\
(\mathrm{N}=139)\end{array}$ & $\begin{array}{c}\text { Third Place } \\
\text { Socializers } \\
(\mathbf{N}=\mathbf{1 8})\end{array}$ & $\begin{array}{l}\text { Community Center } \\
\text { Socializers }(\mathbf{N}=\mathbf{3 4})\end{array}$ & $\begin{array}{c}\text { Non- } \\
\text { Socializers } \\
(\mathbf{N}=\mathbf{2 2}) \\
\end{array}$ & $(N=213)$ & $X^{2}$ or $F$ (sig.) \\
\hline \multicolumn{7}{|c|}{ Physically challenged } \\
\hline Yes (\%) & 36 & 11 & 18 & 39 & 10 & $8.409(0.038)$ \\
\hline No (\%) & 64 & 89 & 82 & 61 & 69 & \\
\hline \multicolumn{7}{|l|}{ Walks } \\
\hline Yes (\%) & 94 & 100 & 97 & 73 & 93 & $\begin{array}{l}16.343 \\
(0.001)\end{array}$ \\
\hline No (\%) & 6 & 0 & 3 & 27 & 7 & \\
\hline \multicolumn{7}{|l|}{ Uses car } \\
\hline Yes (\%) & 81 & 100 & 74 & 50 & 78 & $\begin{array}{l}16.479 \\
(0.001)\end{array}$ \\
\hline No (\%) & 19 & 0 & 27 & 50 & 22 & \\
\hline \multicolumn{7}{|c|}{ Uses public transport } \\
\hline Yes (\%) & 45 & 56 & 53 & 9 & 43 & $\begin{array}{r}13.016 \\
(0.005) \\
\end{array}$ \\
\hline No $(\%)$ & 55 & 44 & 47 & 91 & 57 & \\
\hline \multicolumn{7}{|c|}{ Uses bicycle } \\
\hline Yes (\%) & 80 & 94 & 77 & 50 & 78 & $\begin{array}{l}13.334 \\
(0.004)\end{array}$ \\
\hline No (\%) & 20 & 6 & 24 & 50 & 22 & \\
\hline
\end{tabular}

\section{Conclusions}

Recognizing the importance of social activities for preventing loneliness and stimulating mental and physical health of senior citizens, this study has examined the heterogeneity in their choices for social activity location types. For this study diary data were collected in 2014 in Noord-Limburg in the Netherlands among 213 respondents aged 65 or over. Based on these data a latent class multinomial logit model was estimated. Three segments were identified, showing different parameters for social interaction locations: home socializers, third place socializers and community center socializers. A fourth segment, non-socializers, consisted of the respondents who did not record any interactions in the two diary days.

Using Chi Square and ANOVA tests, significant differences were found between the segments regarding age, education, income, household composition, volunteering, perceived loneliness and health. The third place socializers are younger, wealthier, healthier, higher educated, and more likely to live with a partner, whereas the non-socializers are older, lower educated, more often single, more often lonely and less healthy. The community center socializers are most likely to have a low income, live alone and live in suburban areas. Regarding mobility the results show significant differences between the segments as well. The results suggest that all third place socializers walk and drive, and the majority cycles and uses public transport, whereas only half of the non-socializers uses a car or bicycle, $9 \%$ uses public transport and $73 \%$ walks. 
There are some shortcomings to this study, some of which might be addressed in future research. Our data collection covered data on face-to-face social contacts at different types of locations. Social interactions other than face-to-face, for instance telephone calls or emails, were not included in this research, whereas these ICT-mediated contacts might play a role in social network maintenance and the prevention of loneliness of older adults. We did not collect detailed information on the social activity locations, such as address or quality of the location, although these location characteristics are likely to affect their use. We did not collect data on the content of the social interaction either. Moreover, the data were collected during the winter, which is likely to have implications for the recorded social behavior. It would be preferable to spread the data collection over all seasons. A final shortcoming of our study is the fact that the sample is relatively small. As a result, some of the segments contain only few observations.

Despite these shortcomings, the findings of this study are relevant for health and social welfare services for older people, local governments and planners. In order to support healthy ageing in place, residential environments should provide the necessary opportunities for social interaction of various segments of the aging population. As indicated by the results, there is a specific segment of lower income elderly for whom the community center seems to be an important location for social contact. While many community centers are disappearing, local policy makers should strive to maintain them to promote social participation of the elderly.

While our latent class analysis focused on the social interactions and their locations, $10 \%$ of the sample did not record any social interactions during the two survey days. It is important to pay attention to this segment of elderly, as they are the most vulnerable group, with lower levels of mobility and health and a higher propensity to feeling lonely.

The results suggest that, in addition to personal characteristics, mobility plays an important role in social activity patterns of older adults. The more mobile elderly showed a larger variety of social activity locations. Stimulating their mobility, for instance by providing safe and accessible public transport and walkable neighborhoods, could promote social participation and health of older adults.

\section{Acknowledgments}

This research received no specific grant from any funding agency.

\section{Author Contributions}

Boy de Kleijn performed the data collection. Pauline van den Berg performed the analyses. Pauline van den Berg, Astrid Kemperman and Aloys Borgers wrote the manuscript.

\section{Conflicts of Interest}

The authors declare no conflict of interest.

\section{References}

1. Oldenburg, R. The Great Good Place; Marlow: New York, USA, 1989.

2. Hickman, P. "Third places" and social interaction in deprived neighborhoods in Great Britain. J. Hous. Built Environ. 2013, 28, 221-236. 
3. CBS Fewer shopping and other facilities across the board. Available online: http://www.cbs.nl/enGB/menu/themas/bedrijven/publicaties/artikelen/archief/2007/2007-2097wm.htm?Languageswitch= on (accessed on 25 August 2015).

4. British Columbia Community. Engagement and Connection. Available online: http://www2. gov.bc.ca/gov/topic.page?id=7DAC12F9A9384D4E81682A42302F544D (accessed on 25 August 2015).

5. Tacken, M. Mobility of the elderly in time and space in the Netherlands: An analysis of the Dutch national travel survey. Transportation 1998, 25, 379-393.

6. Alsnih, R.; Hensher, D. The mobility and accessibility expectations of seniors in an ageing population. Transp. Res. Pt. A-Policy Pract. 2003, 37, 903-916.

7. Silvis, J.; Niemeier, D. Social Network and Dwelling Characteristics that Influence Ridesharing Behavior of Seniors. In Proceedings of the 88th Annual Meeting of the Transportation Research Board, Washington, DC, USA, 11-15 January 2009.

8. Mercado, R.; Páez, A. Determinants of distance traveled with a focus on the elderly: A multilevel analysis in the Hamilton CMA, Canada. J. Transp. Geogr. 2009, 17, 65-76

9. Mohammadian, K.; Karimi, B.; Pourabdollahi, Z.; Frignani, M. Modeling Seniors' Activity-Travel Data; Illinois Center for Transporation: Rantoul, IL, USA, 2013.

10. Horner, M.W.; Duncan, M.D.; Wood, B.S.; Valsez-Torres, Y.; Stansbury, C. Do aging populations have differential accessibility to activities? Analyzing the spatial structure of social, professional, and business opportunities. Travel Behav. Soc. 2015, 2, 182-191.

11. Rosenbloom, S. Sustainability and automobility among the elderly: And international assessment. Transportation 2001, 28, 375-408.

12. Collia, D.; Sharp, J.; Giesbrecht, L. The 2001 national household travel survey: A look into the travel patterns of older Americans. J. Safety Res. 2003, 34, 461-470.

13. Páez, A.; Scott, D.; Potoglou, D.; Kanaroglou, P.; Newbold, K. A Mixed Ordered Probit Analysis of Elderly Trip Generation in the Hamilton CMA. In Proceedings of 11th International Conference on Travel Behaviour Research, Kyoto, Japan, 16-20 August 2006.

14. Schmöcker, J.; Quddus, M.; Noland, R.; Bell, M. Estimating Trip Generation of Elderly and Disabled People: An Analysis of London Data. In Proceedings of the 84th Annual Meeting of the Transportation Research Board, Washington, DC, USA, 9-13 January 2005

15. Banister, D.; Bowling, A. Quality of life for the elderly: The transport dimension. Transport. Policy 2004, 11, 105-115.

16. Newbold, K.; Scott, D.; Spinney, J.; Kanaroglou, P.; Páez, A. Travel behavior within Canada’s older population: A cohort analysis. J. Transp. Geogr. 2005, 13, 340-351.

17. Kim, S.; Ulfarsson, G. The Travel Mode Choice of the Elderly: Effects of Personal, Household, Neighborhood and Trip Characteristics. In Proceedings of the 83th Annual Meeting of the Transportation Research Board, Washington, DC, USA, 11-15 January 2004

18. Kemperman, A.; Timmermans, H. Influences of the Built Environment on Walking and Cycling of Latent Segments of the Ageing Population. In Proceedings of the 88th Annual Meeting of the Transportation Research Board, Washington, DC, USA, 11-15 January 2009.

19. Van den Berg, P.E.W.; Arentze, T.A.; Timmermans, H.J.P. Estimating social travel demand of senior citizens in the Netherlands. J. Transp. Geogr. 2011, 19, 323-331 
20. Aoki, R.; Ohno, Y.; Tamakoshi, A.; Kawakami, N.; Nagai, M.; Hashimoto, S.; Ikari, A.; Shimizu, H.; Sakata, K.; Kawamura, T.; Wakai, K; Senda, M. Lifestyle determinants for social activity levels among the Japanese elderly. Arch. Gerontol. Geriatr. 1996, 22, 271-286.

21. Kemperman, A.; Arentze, T.A.; Timmermans, H.J.P. Social Commitments and Activity-Travel Scheduling Decisions. In Proceedings of the 85th Annual Meeting of the Transportation Research Board, Washington, DC, USA, 22-26 January 2006.

22. Carrasco, J.A.; Miller, E.J. Exploring the propensity to perform social activities: A social networks approach. Transportation 2006, 33, 463-480.

23. Farber, S.; Páez, A. My car, my friends, and me: An exploratory analysis of auto mobility and social activities. J. Transp. Geogr. 2009, 17, 216-225.

24. Van den Berg, P.E.W.; Arentze, T.A.; Timmermans, H.J.P. Size and composition of ego-centered social networks and their effect on travel distance and contact frequency. Transp. Res. Rec. 2009, 2135, 1-9.

25. Hawkley, L.C.; Hughes, M.E.; Waite, L.J.; Masi, C.M.; Thisted, R.A.; Cacioppo, J.T. From social structural factors to perceptions of relationship quality and loneliness: The Chicago health, aging, and social relations study. J. Gerontol. Ser. B-Psycho.l Sci. 2008, 63, S375-S384.

26. Scharf, T.; de Jong Gierveld, J. Loneliness in urban neighborhoods: An Anglo-Dutch comparison. Eur. J. Ageing 2008, 5, 103-115

27. De Jong Gierveld, J.; Van Tilburg T., The de Jong Gierveld short scales for emotional and social loneliness: Tested on data from seven countries in the UN generations and gender surveys. Eur. J. Ageing 2010, 7, 121-130.

28. Pino L.; González-Vélez, A.E.; Prieto-Flores, M.E.; Ayala, A., Fernandez-Mayoralas, G.; Rojo-Perez, F.; Martinez-Martin, P.;Forjaz, M.J. Self-perceived health and quality of life by activity status in community-dwelling older adults. Int. Geriatr. Gerontol. 2014, 14, 464-473.

29. Weijs-Perrée, M.; van den Berg, P.E.W.; Kemperman, A.D.A.M.; Arentze, T.A. Factors influencing social satisfaction and loneliness in an ageing society: A path analysis. J. Transp. Geogr. 2015, 45, 24-31.

30. Van den Berg, P.E.W.; Kemperman, A.D.A.M.; De Kleijn, B.; Borgers, A.W.J. Ageing and loneliness: the role of mobility and the built environment. Travel Behav. Soc. 2015, doi:10.1016/j.tbs.2015.03.001

31. Mokhtarian, P.; Salomon, I.; Handy, S. The impacts of ICT on leisure activities and travel: A conceptual exploration. Transportation 2006, 33, 263-289.

32. Frei, A.; Axhausen, K. Modelling the frequency of contacts in a shrunken world. Arbeitsberichte. Verkehrs.- und Raumplanung. 2008. Available online: http://www.ivt.ethz.ch/oev/ped2012/ vpl/publications/reports/ab532.pdf (accessed on 25 August 2015).

33. Van den Berg, P.E.W.; Arentze, T.A.; Timmermans, H.J.P. A multilevel path analysis of contact frequency between social network members. Int. J. Geogr. Inf. Syst. 2012, 14, 125-141.

34. Carrasco, J.A. Personal network maintenance, face to face interaction, and distance: Studying the role of ICT availability and use. Transp. Res. Rec. 2011, 2231, 120-128.

35. Cummings, J.N.; Butler, B.; Kraut, R. The quality of online social relationships. Communication 2002, 45, 103-108

36. Völker, B.; Flap, H. Sixteen million neighbors. A multilevel study of the role of neighbors in the personal networks of the Dutch. Urban. Aff. Rev. 2007, 43, 256-284. 
37. Van den Berg, P.E.W.; Arentze, T.A.; Timmermans, H.J.P. A multilevel analysis of factors influencing local social interaction. Transportation forthcoming.

38. Centers for Disease Control and Prevention. Healthy Places Terminology. Available online: http://www.cdc.gov/healthyplaces/terminology.htm (accessed on 25 August 2015).

39. Talen, E. The social doctrine of new urbanism. Urban Studies 1999, 36, 1361-1379.

40. Dempsey, N.; Brown, C.; Bramley, G. The key to sustainable urban development in UK cities? The influence of density on social sustainability. Prog. Plann. 2012, 77, 89-141.

41. Francis, J.; Giles-Corti, B.; Wood, L.; Knuiman, M. Creating sense of community: The role of public space. J. Environ. Psychol. 2012, 32, 401-409.

42. Whalen, K. E.; Paez, A.; Bhat, C.; Moniruzzaman, M.; Paleti, R. T-communities and sense of community in a university town: Evidence from a student sample using a spatial ordered-response model. Urban Studies 2012, 49, 1357-1376.

43. Van den Berg, P.E.W.; Kemperman, A.D.A.M.; Timmermans, H.J.P. Social Interaction Location Choice. A Latent Class Modeling Approach. Ann. Amer. Assoc. Gynecol. 2014, 104, 959-972.

44. Greene, W.H. Nlogit. Version 3.0 Reference Guide; Econometric Software: Plainview, NY, USA, 2002.

(C) 2015 by the authors; licensee MDPI, Basel, Switzerland. This article is an open access article distributed under the terms and conditions of the Creative Commons Attribution license (http://creativecommons.org/licenses/by/4.0/). 